\title{
Long-Term Complications of Hypospadias Repair: A Ten-Year Experience from Northern Zone of Tanzania
}

This article was published in the following Dove Press journal: Research and Reports in Urology

\author{
Mbarouk Mohammed' \\ Frank Bright' \\ Alfred Mteta' \\ Jasper Mbwambo' \\ Bartholomeo Nicholaus \\ Ngowi (D) \\ Orgeness Mbwambo' \\ Sidney Yongolo ${ }^{2}$ \\ Andrew Mganga (iD) ${ }^{3}$ \\ 'Department of Urology, Faculty of \\ Medicine, Kilimanjaro Christian Medical \\ University College, Moshi, Tanzania; \\ ${ }^{2}$ Department of Urology, Faculty of \\ Medicine, Muhimbili University of Health \\ and Allied Science, Dar es Salaam, \\ Tanzania; ${ }^{3}$ Institute of Public Health, \\ Kilimanjaro Christian Medical University \\ College, Moshi, Tanzania
}

Correspondence: Mbarouk Mohammed Email mbaroukmohd28I@gmail.com

\begin{abstract}
Background: Hypospadias is one of the commonest congenital penile abnormalities in newborn males. The external urethral opening can be located anywhere from the glans penis along the ventral aspect of the shaft of the penis up to the scrotum or the perineum in extreme cases. The condition has a huge impact on the patient's psychological, emotional and sexual well-being.
\end{abstract}

Aim: To determine the proportion of patients who develop long-term complications after hypospadias repair and its associated risk factors.

Methods: This was a hospital-based analytical cross-sectional study, conducted at KCMC Urology Institute from January 2009 to December 2018 and all children were followed up for 1-year post-operatively. A structural data sheet was used to collect information from patients' files. Study parameters include age, location of hypospadias, surgical technique, surgeon experience, chordee, suture size, materials to assess the association with long-term complications.

Results: A total of 254 patients were included in the study, the majority were aged more than 2 years $(71.83 \%)$ with mean age at operation (SD) of $4.74 \pm 2.99$ years. Distal types were the most common type of hypospadias (125 patients; $50 \%)$, and 51 patients $(20 \%)$ had severe chordee. Tubularized incised plate (TIP) repair was the most common technique (130 patients; $51.59 \%$ ). The number of patients with long-term complications following hypospadias repair was $156(61.60 \%)$ and urethrocutaneous fistula(UCF) accounted for $40.5 \%$. The surgeon's experience, location of hypospadias, surgical technique and associated chordee were significant predictors of long-term complications of hypospadias repair.

Conclusion: Tubularized incised plate urethroplasty is a safe and reliable method of hypospadias repair. Proximal hypospadias with severe chordee still remain a challenge.

Keywords: hypospadias, long-term complication

\section{Background}

Hypospadias is a common congenital abnormality of the anterior part of the male urethra and penile development. ${ }^{1}$ It is characterized by three classical features; an abnormal location of the external urethral meatus, abnormal ventral curvature of the penis and dorsal hooded prepuce. ${ }^{1-4}$

The condition is diagnosed clinically and treated surgically with several aims, including psychological, to allow voiding in a standing position, and to allow insemination of sperm in the proper place. Although there are various surgical techniques available for hypospadias repair, treatment is still a challenge because of 
associated complications. As a result, long-term complications of hypospadias repair are reported in $30 \%$ of these operations globally. ${ }^{4-8}$

There are many risk factors for long-term complications of hypospadias repair, such as severity of hypospadias, location of hypospadias, surgical repair technique, age at operation, preoperative hormonal therapy, dressing technique and type of suture material. ${ }^{7}$ At our Centre we perform one to two hypospadias operations per month, and some of them develop various complications.

The aim of this study was to determine the frequency of long-term complications and its associated risk.

\section{Methods}

\section{Study Design}

It was a hospital-based analytical cross-sectional study involving all patients who underwent hypospadias repair from 2009 to 2018.

\section{Study Population and Data Sources}

The record books of patients who underwent hypospadias repair from January 2009 to December 2018 at KCMC Zonal Referral and Teaching Hospital in Tanzania were retrieved from the medical records. A pre-tested structural data collection form was used to extract information from the patient record books. Records of these patients from the time of operation up to 1-year post-operative were extracted from their books.

The ethical clearance and permission to conduct this study from retrospective review was obtained from KCMUCo Research and Ethical committee (2351) and Institute of Urology at KCMC respectively. All patients' information was kept confidential: no direct patient identities were used in this study.

\section{Outcomes and Explanatory Variables}

The main study outcome included was long-term complication of hypospadias repair (urethrocutaneous fistula, meatal stenosis, urethral stricture, relapse chordee formation and meatal stenosis)

Explanatory variables included in the study were age at operation, types of hypospadias, surgical experience $(<5$ cases operated, $>5$ cases operated), surgical technique, suture material, suture technique, type of dressing, presence of chordee (mild $0-20^{\circ}$, moderate $30-40^{\circ}$, severe $>50^{\circ}$ ).

\section{Statistical Analysis}

Multivariable logistic regression was used to model the relationship between exposure and outcomes variables. The magnitude of association was determined using crude prevalence ratio with $95 \%$ confidence interval. Statistical significance was set at $\mathrm{p}$ value of $<0.05$.

Table I Distribution of Characteristics from the Study Population

\begin{tabular}{|c|c|}
\hline Variables & $n(\%)$ \\
\hline Age (mean (sd)) & $4.74(2.99)$ \\
\hline \multicolumn{2}{|l|}{ Age at time of operation } \\
\hline Less than 2 years & $71(28.17)$ \\
\hline More than 2 years & $|8|(7 \mid .83)$ \\
\hline \multicolumn{2}{|l|}{ Surgeon experience } \\
\hline$<5$ cases operated & $126(50)$ \\
\hline$>5$ cases operated & $126(50)$ \\
\hline \multicolumn{2}{|l|}{ Suture size } \\
\hline 3 & $4(1.59)$ \\
\hline 4 & $163(64.68)$ \\
\hline 5 & $49(19.44)$ \\
\hline 6 & $36(14.29)$ \\
\hline \multicolumn{2}{|l|}{ Type of suture material } \\
\hline Monocryl & $2 \mathrm{I}(8.33)$ \\
\hline Pds & |4(5.56) \\
\hline Vicryl & $217(86.11)$ \\
\hline \multicolumn{2}{|l|}{ Suture technique } \\
\hline Continuous & $5(1.98)$ \\
\hline Interrupted & $5(1.98)$ \\
\hline Subcuticular & $242(96.03)$ \\
\hline \multicolumn{2}{|l|}{ Location of hypospadias } \\
\hline Distal & $125(49.6)$ \\
\hline Mild & $47(18.65)$ \\
\hline Proximal & $80(31.75)$ \\
\hline \multicolumn{2}{|l|}{ Surgical technique } \\
\hline Ducket & $32(12.7)$ \\
\hline MAGPI & $2(0.79)$ \\
\hline Mathias technique & $15(5.95)$ \\
\hline Snodgrass & $130(5 \mid .59)$ \\
\hline Staged hypospadias repair & $69(27.38)$ \\
\hline Onlay/inlay & $4(1.59)$ \\
\hline \multicolumn{2}{|l|}{ Chordee } \\
\hline Mild & $36(14.29)$ \\
\hline Moderate & $20(7.94)$ \\
\hline Severe & $5 \mathrm{I}(20.24)$ \\
\hline No chordee & $145(57.54)$ \\
\hline Total & $252(100.00)$ \\
\hline
\end{tabular}




\section{Distribution of long term complications among children underwent \\ hypospadias repair from 2009- 2019}

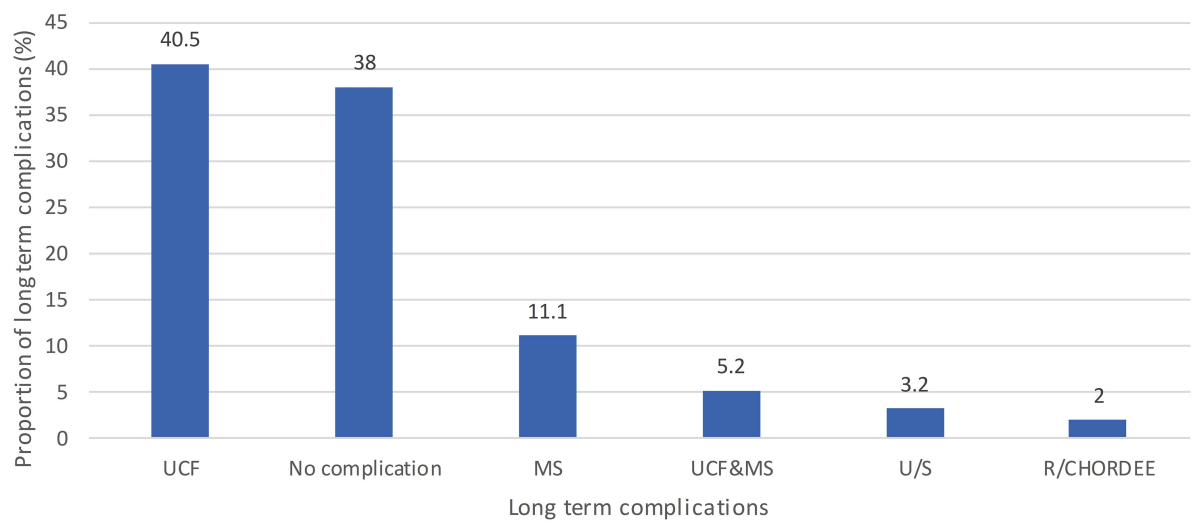

Figure I Distribution of long-term complications among children who underwent hypospadias repair.

The power of the study was obtained using Kirkwood and Sterne formula (2003). ${ }^{9}$

\section{Results}

There were 254 patients who underwent hypospadias repair between 2009 and 2018. Two patients had missing information in the record book and were excluded and therefore 252 were included in the analysis. These patients were followed up for 12 months post- operatively.

Table 1 shows the general characteristics of the study population; the majority of patients were aged 2 years and above (181; 71.83\%) (mean age (SD) $4.74 \pm 2.99$ years). The distal type was the most common type of hypospadias $(125 ; 50 \%)$. The majority of patients underwent the Snodgrass repair technique $(130 ; 51.59 \%)$. The severe form of chordee $(51 ; 20 \%)$ was the most common among hypospadias patients. The subcuticular suturing technique was most practised during the repair $(294 ; 96.03 \%)$ and four zero Vicryl suture material was used in 163 (64.68\%). Just over half of the study subjects (126) were operated on by experienced surgeons.

Figure 1 shows the proportion of long-term complications. UCF was the most common complication encountered (40.5\%), followed by meatal stenosis (11.1\%). Combined UCF and meatal stenosis accounted for 5.2\%. There were a few cases of urethral stricture and relapse of chordee (3.2\% and $2 \%$, respectively).

Table 2 indicates the proportion of long-term complications and their associated factors. The majority of patients $(156 ; 61.60 \%)$ developed at least one long-term complication. Surgeon experience, location of hypospadias, surgical technique and presence of chordee were statistically significantly associated with development of at least one long-term complication of hypospadias repair $(\mathrm{p}<0.001)$.

Table 3 shows crude and multivariable analysis for the association between long-term outcomes and significant predictors.

Adjusted for the effect of location, surgical technique and chordee, the prevalence of having at least one long-term complication among children who were operated on by a surgeon with more than five cases experience was $40 \%$ lower compared with those children who were operated on by a surgeon with less than five cases experience $(\mathrm{CR}=0.6 ; 95 \%$ CI: $0.43-0.84$; $\mathrm{p}=0.003$ ).

However, those children who underwent the Snodgrass technique had a long-term complication prevalence of $46 \%$ lower compared with other surgical techniques $(\mathrm{CR}=0.54 ; 95 \% \mathrm{CI}: 0.31-0.93 ; \mathrm{p}=0.028)$ after adjusting for effect of location, surgeon experience and presence of chordee.

Adjusting for the effect of surgeon experience, surgical technique and chordee the prevalence of having at least one long-term complication among children who had distal type of hypospadias was $12 \%$ higher compared with those children who had a mild type of hypospadias $(\mathrm{CR}=1.12 ; 95 \%$ CI: $0.62-2.03, \mathrm{p}=0.701)$.

However, after adjusting for the effect of location, surgeon experience and surgical technique, the prevalence of having at least one long-term complication among children with severe chordee was 55\% higher compared with those with no chordee $(\mathrm{CR}=1.55 ; 95 \% \mathrm{CI}: 0.74-3.24$; $\mathrm{p}=0.26$ ). 
Table 2 Relationship Between Characteristics and Long-Term Outcomes

\begin{tabular}{|c|c|c|}
\hline \multirow[t]{2}{*}{ Variables } & \multicolumn{2}{|c|}{$\begin{array}{l}\text { Patients with At Least One } \\
\text { Long-Term Outcome }\end{array}$} \\
\hline & $n(\%)$ & p-value \\
\hline $\begin{array}{l}\text { Age at time of operation } \\
\text { Less than } 2 \text { years } \\
\text { More than } 2 \text { years }\end{array}$ & $\begin{array}{l}4 I(57.75) \\
I I 5(63.54)\end{array}$ & 0.395 \\
\hline $\begin{array}{l}\text { Surgeon experience } \\
\quad<5 \text { cases operated } \\
>5 \text { cases operated }\end{array}$ & $\begin{array}{l}100(79.37) \\
56(44.44)\end{array}$ & $<0.001$ \\
\hline $\begin{array}{l}\text { Suture size } \\
3 \\
4 \\
5 \\
6\end{array}$ & $\begin{array}{l}2(50) \\
106(65.03) \\
32(65.31) \\
16(44.44)\end{array}$ & 0.109 \\
\hline $\begin{array}{l}\text { Type of suture material } \\
\text { Monocryl } \\
\text { Pds } \\
\text { Vicryl }\end{array}$ & $\begin{array}{l}13(61.9) \\
10(71.43) \\
133(61.29)\end{array}$ & 0.78 \\
\hline $\begin{array}{l}\text { Suture technique } \\
\text { Continuous } \\
\text { Interrupted } \\
\text { Subcuticular }\end{array}$ & $\begin{array}{l}3(60) \\
4(80) \\
149(6 \mid .57)\end{array}$ & 0.879 \\
\hline $\begin{array}{l}\text { Location of hypospadias } \\
\text { Distal } \\
\text { Mild } \\
\text { Proximal }\end{array}$ & $\begin{array}{l}54(43.2) \\
32(68.09) \\
70(87.5)\end{array}$ & $<0.001$ \\
\hline $\begin{array}{l}\text { Surgical technique } \\
\text { Ducket } \\
\text { Magpi } \\
\text { Mathias technique } \\
\text { Snodgrass } \\
\text { Staged hypospadias repair } \\
\text { Onlay/inlay }\end{array}$ & $\begin{array}{l}25(78.13) \\
2(100) \\
13(86.67) \\
51(39.23) \\
61(88.41) \\
4(100)\end{array}$ & $<0.001$ \\
\hline $\begin{array}{l}\text { Chordee } \\
\text { Mild } \\
\text { Moderate } \\
\text { Severe } \\
\text { No chordee }\end{array}$ & $\begin{array}{l}26(72.22) \\
19(95) \\
47(92.16) \\
64(44.14)\end{array}$ & $<0.001$ \\
\hline Total & $156(61.60)$ & \\
\hline
\end{tabular}

\section{Discussion}

\section{Proportion of Long-Term Complication}

The proportion of study participants who developed at least one long-term complication was $61.60 \%$ (156 of 252). UCF was the most common complication accounting for $40.5 \%$ followed by meatal stenosis at $11.1 \%$. This finding is similar to a study done in Nigeria wherethe proportion of long-term complications was $50 \%$, UCF being most common (38\%) followed by meatal stenosis at $12.5 \% .^{10}$

However, the finding is different from a study done in France where the prevalence was $36.2 \%$ and UCF accounted for $12.9 \%$, meatal stenosis $8.2 \%$ and relapse of chordee was $4.5 \%{ }^{7}$ Our figures in the current study are probably higher because we do not use magnifying glasses in these delicate surgeries and this predisposes to higher complication rates.

Age below 2 years had $26 \%$ and age more than 2 years had $41 \%$ long-term complications. This is most likely due to feasibility of post-operative management and lower psychological impacts with better healing process in children below 2 years. ${ }^{3,7}$

\section{Risk Factors and Long-Term Complications}

In our study some risk factors have been picked up which were associated with long-term complications of hypospadias repair. These include surgeon experience, location of hypospadias, surgical technique and associated factors.

The prevalence of having long-term complications was $44 \%$ lower among children who were operated on by an experienced surgeon compared with a less experienced surgeon. This study is consistent with a study done in Egypt which showed significant impact on success with reduction of long-term complications from $35 \%$ to $9 \%$ with experienced surgeons. That fewer complications are observed following operations by experienced surgeons is probably due to better hand skills, improvement on learning curve and proper pre- and intra-operative judgement in choosing the best technique. ${ }^{11}$

The proximal type of hypospadias has been shown to have $29 \%$ higher chance of developing long-term complications compared with middle and distal types. UCF was observed in $66 \%$ of proximal, $51 \%$ in middle and $20 \%$ in distal, especially if it is associated with severe chordee.

There is much variation with a study done in Canada which showed $15-56 \%$ long-term complications in proximal type associated with severe chordee and a study in Korea reporting $48.9 \%$ long-term complications in proximal, $33.8 \%$ middle and $10.3 \%$ distal; this was due to the small number of patients who had proximal types of hypospadias and most of them had moderate chordee so they underwent the Snodgrass technique. ${ }^{12,13}$ This could 
Table 3 Crude and Multivariable Analysis for the Association Between Long-Term Outcomes and Significant Predictors

\begin{tabular}{|c|c|c|c|c|}
\hline \multirow[t]{2}{*}{ Variables } & \multicolumn{2}{|l|}{ Crude } & \multicolumn{2}{|l|}{ Multivariable } \\
\hline & Prevalence Ratio & p-value $(95 \% \mathrm{Cl})$ & Prevalence Ratio & p-value(95\% Cl) \\
\hline \multicolumn{5}{|l|}{ Surgeon experience } \\
\hline$<5$ cases operated & I & & I & \\
\hline$>5$ cases operated & 0.56 & $0.00 I(0.4-0.78)$ & 0.6 & $0.003(0.43-0.84)$ \\
\hline \multicolumn{5}{|l|}{ Location of hypospadias } \\
\hline Mild & I & & 1 & \\
\hline Distal & 0.63 & $0.04 I(0.4 I-0.98)$ & 1.12 & $0.70 I(0.62-2.03)$ \\
\hline Proximal & 1.29 & $0.240(0.85-1.95)$ & 1.01 & $0.977(0.52-1.95)$ \\
\hline \multicolumn{5}{|l|}{ Surgical technique } \\
\hline Ducket & I & & I & \\
\hline MAGPI & 1.28 & $0.737(0.30-5.40)$ & 0.9 & $0.89 \mid(0.21-3.96)$ \\
\hline Mathias technique & I.II & $0.762(0.57-2.17)$ & 1.13 & $0.718(0.58-2.23)$ \\
\hline Snodgrass & 0.5 & $0.005(0.3 \mathrm{I}-0.8 \mathrm{I})$ & 0.54 & $0.028(0.31-0.93)$ \\
\hline Staged hypospadias repair & 1.13 & $0.603(0.71-1.80)$ & 0.83 & $0.570(0.44-1.58)$ \\
\hline Onlay/inlay & 1.28 & $0.647(0.45-3.68)$ & 1.12 & $0.840(0.38-3.31)$ \\
\hline \multicolumn{5}{|l|}{ Chordee } \\
\hline No chordee & I & & I & \\
\hline Moderate & 1.64 & $0.034(1.04-2.58)$ & 1.31 & $0.349(0.74-2.32)$ \\
\hline Severe & 2.15 & $0.003(1.29-3.59)$ & 1.55 & $0.246(0.74-3.24)$ \\
\hline Mild & 2.09 & $<0.001(1.43-3.04)$ & 1.57 & $0.237(0.74-3.34)$ \\
\hline
\end{tabular}

be explained in our study by the proximal type of hypospadias being $31.7 \%$ and $65 \%$ of patients with severe chordee underwent staged hypospadias repair.

Regarding surgical technique, the prevalence of developing long-term complications following the Snodgrass technique was 50\% lower compared with Ducket, MAGPI, Mathew, Onlay/Inlay and staged urethroplasty. UCF was $\sim 20 \%$, meatal stenosis $13 \%$ and urethral stricture $1.6 \%$ with the Snodgrass technique; complications were higher following Ducket, with 59\% UCF, $12 \%$ meatal stenosis, 3\% urethral stricture or following staged urethroplasty, with $62 \%$ UCF, $4.3 \%$ meatal stenosis, $5.8 \%$ urethral stricture. Snodgrass was the common surgical technique and seems to have better outcomes especially in distal type. ${ }^{14}$

Staged urethroplasty was the most common procedure in proximal types of hypospadias especially if it is associated with chordee (65\%). This finding is consistent with studies done in Pakistan and Ghana in which Snodgrass was the most common surgical technique (54\% and $73 \%$, respectively) and its level of associated long-term complications was $16 \%$ and $30 \%$ lower, respectively compared with other techniques, where UCF was $26 \%$ and $20 \%$, respectively and the highest complication rate was seen in island flap staged urethroplasty for proximal hypospadias with severe chordee of about $60 \%$. This was due to most of the patients with severe chordee undergoing staged urethroplasty. ${ }^{15,16}$

A study done in Pennsylvania shows different results, where single staged hypospadias repair done in proximal form was associated with a high prevalence of long-term complications at between $62 \%$ and $49 \% .{ }^{17}$

\section{Conclusion}

Distal hypospadias is the most common type. TIP and surgical experience are protective factors against longterm complications.

Proximal hypospadias with a severe form of chordee $>30^{\circ}$ still remain a challenge according to our study.

\section{Abbreviations}

DHT, dihydrotestosterone; DFP, dorsal preputial flap; HCG, human chorionic gonadotropin; KCMUCo, Kilimanjaro Christian Medical University College; KCMC, Kilimanjaro Christian Medical Centre; LUTS, lower urinary tract symptoms; MAGPI, Meatal Advancement and Glanuloplasty; PHS, preoperative hormonal stimulation; PDS, polydioxanone; TIP, tubularized incised plate; T, testosterone; UCF, urethrocutaneous fistula. 


\section{Ethical Approval}

Research ethical clearance was received from the KCMUCO Research and Ethical committee (certificate no 2351), patient informed consent was not required due to the anonymized patient data. It was conducted in accordance with the Declaration of Helsinki and permission was obtained from the head of the Urology Institute.

\section{Consent for Publication}

I Dr. Mbarouk Mohammed hereby declare, I participated in the study and development of manuscript entitled "Long-term complications of hypospadias repair: A tenyear experience from Northern Zone of Tanzania" I have read the final version and give consent to be published in Dovepress Urology.

\section{Acknowledgments}

This work was funded by the Al-Rahma hospital. The authors thank the KCMC hospital director and medical records department for permission to conduct and access the patient file data. This paper was presented at the BMC urology and posted at research square with DOI:10.21203/ rs.3.rs-37958/v1 but finally the article was rejected due to the following reason. 1. It was done in a single centre and it cannot offer a novel contribution to hypospadias literature.

\section{Author Contributions}

The IPH (Andrew Mganga), external Examiner (Prof. Sidney Yongolo) and Urology Institute conceptualised and designed the study, conducted the statistical analysis, drafted the initial manuscript and approved the final manuscript as submitted. Mbarouk Mohammed - corresponding author

1st authors - (Frank Bright, Alfred Kein Mteta, Jasper Said Mbwambo, Nicolaus Bartholomew Ngowi, Orgeness Mbwambo - KCMC Department of Urology.)

2nd authors - Sidney Yongolo - Muhimbili university of health and allied science - external supervisor. 3rd authors - Andrew Mganga - (KCMC Institute of Public Health - Department of Biostatistics).

Note: All authors made a significant contribution to the work reported, whether that is in the conception, study design, execution, acquisition of data, analysis and interpretation, or in all these areas; took part in drafting, revising or critically reviewing the article; gave final approval of the version to be published; have agreed on the journal to which the article has been submitted; and agree to be accountable for all aspects of the work.

\section{Funding}

Al-Rahma Hospital, Zanzibar, Tanzania.

\section{Disclosure}

The authors report no conflicts of interest for this work.

\section{References}

1. Campbell-wash. Campbell-Wash Urology. eleventh ed. Philadelphia, PA: Campbell-Walsh; 2011:4517.

2. Lu W, Tao Y, Wisniewski AB, Frimberger D, Kropp BP. Europe and China: is patient age a factor? Neuphrourol. 2012;4(4):609-612.

3. Of E of paediatric urology. Paediatric Urol. 2008;second edi:213.

4. Keith P, MTV. Embryology - The_developing_human_8;245-260.

5. Okeke AA, Okonkwo CC, Osegbe DN. Prevalence of hypospadias, abdominal and penoscrotal abnormalities among primary school boys in nigerian community. 2003;9(2):59-64.

6. Marrocco G, Vallasciani S, Fiocca G, Calisti A. Hypospadias surgery: a 10-year review Hypospadias surgery: a 10-year review. Pediatric Surg Int. 2004;20(3):200-203.

7. Garnier S, Maillet O, Cereda B, et al. Late surgical correction of hypospadias increases the risk of complications: a series of 501 consecutive patients. BJU Int. 2017;942-947.

8. Buba S. Early diagnosis, repair and common post operative complications of hypospadias. 2014;26:10-13.

9. Betty R Kirkwood, Jonathan AC Sterne, editors. Essential medical statistics. 2nd edition. Wiley-Blackwell: June 2003

10. Evaluation P, Normally full blood count renal function test, urine culture, blood group and cross matching can be done also by looking the anaesthetic risk penile dimensions and psychological risk of genital surgery (13)., The use of testosterone to increase the penile size has controversial now days formerly the surgeons used it to increase the penile dimensions, however penile size is not a limiting factor in most children because there is no technical advantage of delaying surgery (13); Inokhoife O, Atim T. et al. Hypospadias repair and outcome in Abuja, Nigeria: A 5-year single-centre experience. Afr J paediatric Surg. 2015. 12(1):41.

11. Hafez AT, Helmy T. Plate repair for penoscrotal. URL. 2012;79 (2):425-427. doi:http://dx.doi.10.1016/j.urology.2011.10.033.

12. Keays MA, Dave S. Review Current hypospadias management: diagnosis, surgical management, and long-term patient-centred outcomes. Can Urol Assoc J. 2017;11(1-2):S48.

13. Chung J, Choi SH, Kim BS, Chung SK. Pediatric urology risk factors for the development of urethrocutaneous fistula after hypospadias repair: a retrospective study. Korean J Urol. 2012;53(10):711-715. doi:10.4111/kju.2012.53.10.711

14. Jan IA, Mirza F, Ali M, Arian A, Saleem N, Kumar D. Factors influencing the results of surgery for hypospadias: experience at NICH. J Pak Med Assoc. 2004. 54(11):577-579.

15. Hesse AAJ. Hypospadias surgery at korle-bu teaching hospital, ghana: a review of 36 patients. Afr J Paediatric Surg. 2007;4 (2):61-63.

16. Liu G, Yuan J, Feng J, Geng J, Zhang W. Factors Affecting the LongTerm Results of Hypospadias Repairs. 2006:554-559.

17. Long CJ, Chu DI, Tenney RW, et al. Intermediate-term followup of proximal hypospadias repair reveals high complication rate. SC. $J$ Urol. 2016.: doi:10.1016/j.juro.2016.11.054 


\section{Publish your work in this journal}

Research and Reports in Urology is an international, peer-reviewed, open access journal publishing original research, reports, editorials, reviews and commentaries on all aspects of adult and pediatric urology in the clinic and laboratory including the following topics Pathology, pathophysiology of urological disease; Investigation and treatment of urological disease; Pharmacology of drugs used for the treatment of urological disease. The manuscript management system is completely online and includes a very quick and fair peer-review system, which is all easy to use. Visit http://www.dovepress.com/ testimonials.php to read real quotes from published authors.

Submit your manuscript here: https://www.dovepress.com/research-and-reports-in-urology-journal 